\title{
O “VELHO” SUJEITO HISTÓRICO E A LUTA DE ClASSES NA VENEZUELA do SÉCUlo XXI ${ }^{1}$
}

\author{
Flavia Bischain Rosa ${ }^{2}$
}

\begin{abstract}
RESUMO
0 atual debate sobre a reestruturação produtiva e as transformações no chamado "mundo do trabalho" atirou para o escanteio a velha discussão sobre o "papel histórico" do proletariado, de Marx e Engels. A influência de novos atores na luta de classes ganha destaque nas pesquisas atuais. Na contramão deste debate, emergem lutas radicalizadas do operariado venezuelano em meio à chamada "Revolução Bolivariana". As ocupações de fábricas, as manifestações e exigências de controle operário, indicam que a reorganização das forças políticas e sindicais operárias se intensifica sob um contexto do acirramento da luta de classes nesse país.
\end{abstract}

Palavras-chave: Movimento operário. Luta de classes. Reorganização. Governo Chávez.

\section{The “OLD” historical Subject and the 21st CENTURY Class STRUGGLE IN VENEZUELA}

\begin{abstract}
The current debate about productive restructuring and the transformations in the socalled «labor world» has put aside the old discussion about the «historical role» of the proletariat, of Marx and Engels. The influence of new actors in the class struggle is highlighted in present researches. In the opposite side of this debate, radical Venezuelan laborer struggles emerge amidst the so-called "Bolivarian Revolution". The factories occupations, protests and demands of laborer's control indicate that the

\footnotetext{
${ }^{1} 0$ presente artigo é uma reformulação do trabalho "A reorganização do movimento operário venezuelano e sua relação com o governo de Hugo Chávez", apresentado no IV Simpósio Lutas Sociais na América Latina (2010)

${ }^{2}$ Mestranda em Ciências Sociais pela Universidade Estadual de Londrina, Brasil. flavia.bischain@ yahoo.com.br
} 
reorganization of political forces and unions are intensifying under a context of a strongly disputed class struggle.

Keywords: Labour movement. Class struggle. Reorganization. Chavez's government.

\section{UMA BREVE INTRODUÇÃO SOBRE AS TRANSFORMAÇÕES NO “MUNDO DO TRABALHO” E SUAS CONSEQUÊNCIAS NO DEBATE TEÓRICO}
A s mudanças na esfera da produção e na relação capital/trabalho são constantes. No entanto, a literatura que aborda o tema tem destacado 0 período dos últimos 30 anos para indicar uma grande transformação no chamado "mundo do trabalho", que teria reconfigurado o perfil da classe trabalhadora ou, até mesmo, modificado a sua importância para as análises sociológicas atuais.

As principais consequências desta reestruturação produtiva seriam: a diminuição do operariado fabril, o aumento da precarização do trabalho com expansão do trabalho temporário, parcial e terceirizado, a modificação no perfil da classe trabalhadora devido ao forte aumento do trabalho feminino (principalmente nos setores mais precarizados), a expansão do "setor de serviços", a exclusão de trabalhadores "jovens" e "velhos" do mercado de trabalho nos países centrais, a superexploração de imigrantes, mulheres, negros e crianças, assim como o desemprego estrutural (ANTUNES, 1999, p. 191).

Além das mudanças específicas no processo produtivo, o desmoronamento da experiência soviética no Leste Europeu e a ideia de que "o capitalismo venceu" são fatores que tiveram um peso importante no refluxo do movimento operário, gerando uma crise nos partidos comunistas e nos sindicatos que estes dirigiam. A atuação da esquerda, em geral, passou a ser marcada pela institucionalização e pela burocratização. Além do impacto ideológico3n, o chamado "fim do socialismo" acarretou à classe trabalhadora a perda de direitos e conquistas sociais (ANTUNES, 1999, p. 188-189).

Como se sabe, o programa neoliberal implantado a partir da década de 1970, também foi responsável por uma série de derrotas dos trabalhadores provocadas pelas "privatizações aceleradas, enxugamento do Estado, políticas fiscal e monetária sintonizadas com os organismos mundiais de hegemonia do

\footnotetext{
${ }^{3}$ Denominado pelo autor de "social-democratização da esquerda", que passou a atuar de forma subordinada ao capital (ANTUNES, 1999, p. 188).
} 
capital, como o FMI e o BIRD, desmontagem dos direitos sociais dos trabalhadores, controle cerrado ao sindicalismo de esquerda [...]", como afirma Ricardo Antunes (1999, p. 189).

As análises que tratam destas mudanças e da participação política dos trabalhadores têm se voltado para duas abordagens bastante divergentes:

a) As análises que apontam para o fim das classes e o fim da centralidade do trabalho. Apoiando-se no desemprego provocado pelo desenvolvimento tecnológico, muitos teóricos têm decretado a impotência do operariado para conduzir o processo de luta política contra a sociedade capitalista. A classe operária, agora reduzida, teria perdido sua força e seu papel histórico.

A queda nas taxas de sindicalização e do ativismo sindical são, ao lado da reestruturação produtiva, sustentáculos das teses que questionam a centralidade do trabalho apoiando-se no declínio político do operariado:

Vários autores, entre eles Offe (1989), articularam a redução das taxas de sindicalização ao conseqüente enfraquecimento da ação política da classe trabalhadora, ou ainda, para ser mais exato, indicaram que a partir das metamorfoses no "mundo do trabalho" a classe trabalhadora havia se tornado fragmentada e heterogênea (AMORIM, 2006, p. 27).

Na mesma linha da tese de Claus Offe, a produção teórica de Gorz - que afirmava até a década de 1970, que o operariado era o sujeito da transformação - viu no crescimento do mercado informal não assalariado a substituição do operariado por uma "não-classe-de-não-trabalhadores", para a qual o emprego era apenas algo provisório (ORGANISTA, 2006, p. 33).

A sentença de Gorz, "adeus a proletariado", se apóia na ideia de que a microeletrônica dá origem a uma nova ordem, marcada pela diminuição do trabalho e pelo desemprego tecnológico, decorrente da intensa automação e informatização. 0 mercado de trabalho dual seria composto por um centro privilegiado de trabalhadores em tempo integral (cuja tendência é a diminuição) e por uma cada vez mais ampla camada de trabalhadores parciais ou desempregados que não poderiam ser absorvidos. A "não-classe-de-não-trabalhadores", não poderia mais, portanto, ser definida a partir de sua posição no processo produtivo (ORGANISTA, 2006, p. 34-36).

Por estar destinado ao desaparecimento, o operariado industrial não teria mais condições de organizar a resistência dos trabalhadores. Conforme apontou a reflexão de Offe (1989), a luta política se deslocaria para outra esfera: 
a sociedade civil (apud AMORIM, 2006, p. 28). Os movimentos sociais seriam os que poderiam, agora, conduzir a vida política: "A categoria trabalho perderia, então, sua centralidade, dando lugar às preocupações que girariam em torno de questões relativas à ação social como status familiar, questões de gênero, condições de saúde, idade, situações étnicas e processos identitários" (OFFE, 1989 apud AMORIM, 2006, p. 28).

b) Estudos que afirmam a centralidade do trabalho, mas apontam novas configurações das classes sociais.

Contrapondo-se às teses de Gorz, Offe e Habermas, Ricardo Antunes amplia o conceito de proletariado para "classe-que-vive-do-trabalho"^ e destaca que: "Ao contrário, portanto, de se falar em fim do trabalho, parece evidente que o capital conseguiu, em escala mundial, ampliar as esferas de assalariamento e de exploração do trabalho, nas várias formas de precarização, subemprego,part time etc." (ANTUNES, 1999, p. 204).

Estes elementos devem ser considerados como uma forte característica do "novo proletariado", nos termos de Antunes (1999, p. 202). Ou seja, o que está ocorrendo na verdade, não é o desaparecimento do proletariado, mas a mutação de suas características: "Essas mutações criaram, portanto, uma classe trabalhadora ainda mais diferenciada, entre qualificados/desqualificados, mercado formal/ informal, homens/mulheres, jovens/velhos, estáveis/precários, imigrantes/ nacionais etc." (ANTUNES, 1999, p. 191).

Outro elemento a ser considerado, conforme a formulação do autor, é a "proletarização" de trabalhadores assalariados médios (bancários, turismo, setor de serviços em geral) cuja condição de trabalho está cada vez mais degradada e 0 ritmo e a exploração intensificados (ANTUNES, 1999, p. 203-04).

José Henrique Organista também questiona a tese de que se esteja abolindo o trabalho. Para este autor o que se passa é que o capitalismo está "utilizandose da força de trabalho de forma diferenciada. Se antes prevalecia a forma de assalariamento direto, hoje é possível observar que, por meio do processo de externalização e terceirização, se incentiva 0 trabalho por conta própria e 0 empreendedorismo" (ORGANISTA, 2006, p. 38). A vantagem para o capital em criar estes novos "patrões" é que ele se exime da responsabilidade pelo desemprego

\footnotetext{
${ }^{4}$ Entendida como "a totalidade dos assalariados, homens e mulheres que vivem da venda da sua força de trabalho e que são despossuídos dos meios de produção" (ANTUNES, 1999, p. 196, grifo do autor).
} 
já que 0 próprio trabalhador passa a ser responsável por gerar seu trabalho (ORGANISTA, 2006, p. 38).

É inegável a importância de refletir sobre essas mudanças e reconfigurações das classes trabalhadoras. Concordamos neste sentido, com as análises aqui apresentadas que ratificam a centralidade do trabalho como categoria fundamental da sociedade contemporânea, mas, não ignoramos que também existem novos sujeitos que se multiplicam e ocupam os mais variados espaços no cenário da luta política. Neste sentido, concordamos com a proposta de Andréia Galvão (2010) de que é fundamental ao marxismo desenvolver uma teoria dos movimentos sociais, refletindo sobre os limites e o potencial transformador destes movimentos.

Diante de tal reflexão, por que então voltar-se novamente à "velha" classe operária? Está claro que a crítica à negação do trabalho possui diversos porta-vozes - apesar do tema não estar esgotado. Não se pretende aqui aprofundar esse debate. Retomamos o tema da classe operária centralmente por dois motivos: Primeiro porque, se é evidente a importância de analisar as mudanças e novos setores que vão se somando à classe trabalhadora, não está claro, por outro lado, onde fica 0 operariado, propriamente dito, nesta história. Ele continua desempenhando um papel central, "à frente" da classe trabalhadora? Ele cumpre um papel secundário diante de outros atores que estão emergindo? Como anda a potencialidade de sua ação revolucionária?

0 segundo motivo é mais prático: a atenção ao movimento operário aqui se dá porque, no caso venezuelano, é o movimento operário que tem se destacado no processo da luta política do país no último período. Qual é a explicação para isso? Qual é a importância deste fato para o debate sobre a crise política e organizativa do operariado mundial?

Obviamente não será possível responder a todas estas questões, até porque, o que está se chamando de "reorganização do movimento operário na Venezuela" é algo muito recente. Comecemos então, ainda de maneira inicial, por tratar do caso venezuelano.

\section{O PROCESSO DE REORGANIZAÇÃO OPERÁRIA NA VENEZUELA}

$\mathrm{Na}$ contramão da crise política do movimento operário mundial, o fortalecimento das organizações da classe trabalhadora venezuelana se torna

${ }^{5}$ Foram citados neste texto: Antunes, Amorim e Organista, como alguns exemplos.

O “velho” Sujeito históRico E a Luta de CLASSES na Venezuela...

F. B. Rosa

- 301 
visível nos últimos anos, e um grande número de mobilizações tem ocorrido pelo país. Multiplicam-se também, em muitos estados, os protestos dos setores populares por serviços públicos, como água, luz e moradia. 0 que chama a atenção, porém, é o fato de que o movimento operário tem sido, recentemente, o setor mais dinâmico destas lutas. Ocupações de fábricas, greves, concentração de trabalhadores em assembléias, marchas e passeatas organizadas por seus partidos e sindicatos voltam a ser destaque no cenário político nacional: "A finales de 2004 y en la primera mitad de 2005 vimos el inicio de un movimiento de la clase obrera para intentar poner su sello en esta revolución", afirmam ativistas do Frente Revolucionário de Trabajadores de Empresas en Cogestión y Ocupadas, referindo-se ao movimento de ocupações de fábricas, encampado por trabalhadores venezuelanos (MORENO; SANABRIA, 2007).

Segundo a corrente sindical C-CURA (Corriente Clasista, Unitária, Revolucionaria y Autónoma), apesar dos dados apresentados pelo jornal $E l$ Nacional acerca de que 46.000 trabalhadores teriam participado de ocupações de empresas, poderia chegar a 100.000 o número de empregados envolvidos em conflitos diretos com o patrão. Os principais casos foram os das empresas Toyota, Mitsubishi, Metalpress, Firestone, Coca Cola, Cadafe, Planta de Tratamiento de Desechos Sólidos em Mérida, ULA TV, Autotex, Sanitários Maracay e Sidor (C-CURA, 2008, p. 3):

[...] cada día que pasa, las calles y avenidas de las principales ciudades y sobre todo Caracas, han sido tomadas por infinidad de marchas y conflictos por demandas salariales, exigencia al reconocimiento de las convenciones colectivas, defensa de los derechos sindicales, gremios encadenados exigiendo sean atendidos, reclamos por viviendas y servicios públicos: Los trabajadores estamos peleando (USI, 2008, p. 4).

Algumas destas mobilizações tiveram grande impacto político no país. 0 caso da ocupação da fábrica Sanitários Maracay, palco de disputa entre diversas correntes do movimento operário, conferiu um desgaste ao governador do estado de Aragua, após a repressão contra a marcha de 23 de Abril de 2007 que exigia nacionalização da fábrica sob controle dos trabalhadores.

\footnotetext{
${ }^{6} 0$ governador do estado de Aragua, Didalco Bolívar, ordenou que a polícia do estado detivesse os manifestantes. No enfrentamento foram presos 15 operários e feridos 14 por parte da polícia e da Guarda Nacional.
} 
Os operários arrastavam há vários anos uma luta contra a violação do contrato coletivo por parte do patrão que não reconhecia o sindicato. Questionavase a contratação de trabalhadores temporários sem direitos e as condições de super-exploração (horas extras, condições inadequadas de segurança no trabalho e cobranças constantes para ampliar a produção). A mobilização se iniciou devido à tentativa, por parte do patrão, de rebaixar os salários, ameaçando fechar a fábrica. Diante das ameaças, os operários ocuparam as instalações e passaram a gerir a produção em novembro de 20067. Contudo, o governo só anunciou a nacionalização da fábrica em dezembro de 2010, após quatro anos de uma luta incansável por parte dos trabalhadores.

A recente vitória dos operários da siderúrgica SIDOR, nacionalizada em 2008 após intensas mobilizações, culminou na queda do ministro do Trabalho e deu novo fôlego ao movimento sindical venezuelano. Os sidoristas, que participaram ativamente das mobilizações contra o locaute patronal em 2002, vinham realizando, desde 2006, uma série de protestos questionando os baixos salários e reivindicando negociar o acordo coletivo.

0 protesto, que finalizava a greve de 80 horas declarada pelo sindicato para pressionar a empresa, foi reprimido pela Guarda Nacional no dia 14 de março de 2008. No confronto, os operários foram agredidos e atingidos por balas de borracha e bombas de gás lacrimogêneo. Foram presos 53 operários, acusados de cometer delito por fechar vias públicas.

A vitória da nacionalização da SIDOR foi apenas parcial, pois o processo se limitou a uma compra de ações da transnacional. Os terceirizados continuam na mesma situação precária e a melhoria das condições de trabalho ainda está na pauta de reivindicações dos trabalhadores.

\section{A INSTABILIDADE DO REGIME DEMOCRÁTICO-BURGUÊS E A ASCENSÃO DAS LUTAS}

Apesar de se iniciar sob o governo Chávez uma reconfiguração das forças políticas, o processo de reorganização política da classe trabalhadora é anterior. A ascensão das lutas se inicia em 1989 com o Caracazo, em um período de desgaste do regime democrático-burguês venezuelano.

A história das organizações políticas e sindicais do operariado e setores populares foi marcada por um forte vínculo com o Estado e com partidos de massas,

\footnotetext{
${ }^{7} \mathrm{~A}$ atuação do então ministro do Trabalho José Ramon Rivero contra os trabalhadores resultou na desocupação da fábrica em agosto de 2007.
} 
que governavam o país num cenário que ficou conhecido como a democracia "mais sólida" do continente (MALDONADO; FERNÁNDEZ; RODRÍGUES, 2004, p. 72). 0 petróleo, principal fonte de renda do Estado, serviu como um "amortecedor da luta de classes nos períodos de bonança” (MARINGONI, 2004, p. 84).

Contudo, a implantação do neoliberalismo na década de 1980, somada à crise política que se formava, reconfigurou a relação entre as forças políticas. As ideologias neoliberais do Estado mínimo, da flexibilidade na esfera da produção, da liberdade de mercado, começaram a ampliar o seu espaço quando, a partir de 1973, "todo o mundo capitalista avançado caiu numa longa e profunda recessão, combinando, pela primeira vez, baixas taxas de crescimento com altas taxas de inflação" (ANDERSON, 2000, p. 10). A crise política que se abriu no país a partir da adoção do projeto neoliberal e dos escândalos de corrupção que apareciam simultaneamente, enfraqueceu o regime, as instituições políticas e o vínculo que estabeleciam entre si. Tudo desmoronou. Por um lado, os partidos tradicionais como $\mathrm{AD}$ e $\mathrm{COPEI}^{8}$, assim como o próprio regime, começam a ser questionados pela ineficiência administrativa, pelo clientelismo e pela corrupção. Por outro lado, as políticas neoliberais que começavam a ser aplicadas, impunham uma vida com muitos sacrifícios aos trabalhadores.

os vínculos que imperavam até então entre as massas populares e o Estado começam a se esfacelar. Inicia-se um intenso processo de mobilizações que se alastra pelas principais cidades. Margarita López Maya afirma que se inaugurava neste momento uma política de protestos de rua devido ao afastamento dos partidos e sindicatos e a sua incapacidade de responder aos anseios dos setores sociais, que passariam a "atuar por conta própria" (MAYA; SMILDE; STEPHANY, 2002, p. 13-14). Isso leva a crer que a classe trabalhadora tivera passado por um processo de desorganização de suas forças, uma vez que a principal central sindical (Confederación de Trabajadores de Venezuela - CTV) e os partidos de massas eram dirigidos, até então, pelos partidos do governo (AD e COPEI) (CORMENZANA, 2009).

A falta de saídas institucionais, a crise de representatividade dos partidos tradicionais, o esgotamento do modelo rentista e a debilidade dos organismos de Estado são apontados por José Larez Rubio e Juan Romero Jiménez (2002, p. 79) como alguns dos elementos que causaram uma transformação profunda nas relações políticas do país e o declínio do sistema político que imperava desde 1958.

${ }^{8}$ Acción Democratica é fundado em 1941 e junto com o partido COPEI (Comitê de Organização Política Eleitoral Independente), criado em 1946, adquire grande influência sobre o movimento estudantil, sindical e popular. 
Esse seria o pano de fundo para entender o processo de reorganização política dos trabalhadores, que se abre em 1989.

Apenas há pouco tempo alguns setores estavam se reorganizando e combatendo o controle da burocracia sindical e dos antigos partidos de massas. Nesse contexto, a eleição de Chávez é o marco de uma ruptura histórica das massas com as organizações tradicionais. Segundo a professora Nelly Arenas, a eleição de Chávez não significou uma vitória específica dos trabalhadores nas urnas, ou de outra classe em particular com o seu respectivo partido, mas de uma franja de diferentes setores que incluía trabalhadores, classe média, camponeses, trabalhadores informais e fragmentos do empresariado, descontentes com os problemas pelos quais passava o regime: "[A eleição de Chávez] es producto de una fuerte fractura del sistema sociopolítico que dominó en Venezuela desde la reinauguración de la democracia en 1958, fundado en un conjunto de pactos constitutivos" (ARENAS, 2006, p. 43).

\section{Algumas EXPLICAÇÕES POSSÍvEIS PARA O PROCESSO DE REORGANIZAÇÃO POLÍTICA NO PAÍS}

A ruptura das massas com suas direções tradicionais, por um lado, e a ascensão das lutas por outro, parece ter possibilitado uma recomposição de forças da classe trabalhadora. A necessidade de responder à crise política e aos ataques dos patrões, do governo e do neoliberalismo, impulsionou uma reorganização lenta das forças políticas que se intensifica durante o governo de Hugo Chávez. Os principais motivos que justificam esta intensificação podem ser sistematizados da seguinte maneira:

a) Eleição de Chávez: Segundo Margarita Lopez Maya, a chegada de Chávez à presidência teria intensificado a "política de la calle". As pessoas organizavam mobilizações de rua porque queriam expor suas necessidades ao presidente, confiando que seriam atendidas por ele (MAYA; SMILDE; STEPHANY, 2002, p. 16). 0 processo de reorganização se intensifica, no primeiro momento, não para combater o governo, mas para levar os problemas e demandas ao presidente.

b) Golpes e paralisações patronais: : A tentativa de golpe contra Chávez em abril de 2002 - organizada pela Fedecámaras, CTV, uma cúpula da PDVSA

\footnotetext{
${ }^{9}$ Em dezembro de 2001 os setores patronais organizam uma paralisação nacional, com greve na PDVSA e locaute do comércio e da indústria. No ano seguinte a paralisação dura 63 dias e chegou a abalar a estrutura produtiva do país com a interrupção quase total da produção de petróleo, sabotagens e fuga de capitais.
}

O “velho” Sujeito históRico E A Luta de CLASSES na Venezuela...

F. B. Rosa 
e um grupo de militares, com apoio da CIA e de políticos da oposição - e as paralisações e sabotagens patronais são alguns dos fatores que aceleram o processo de reorganização. A necessidade, por parte da classe trabalhadora e de setores populares, de responder a estes ataques fez com que fossem adquirindo experiência de luta e avançassem em sua organização. A criação da União Nacional dos Trabalhadores (UNT) em 2003, por exemplo, é produto de uma tentativa de responder à posição da CTV, que se juntou aos setores golpistas.

c) Acirramento da luta de classes: Apesar da tentativa de Chávez de governar para "todas as classes", o antagonismo de classes ainda assola os trabalhadores e 0 operariado utiliza as experiências adquiridas também para se organizar contra os patrões. 0 caráter ativo que 0 apoio das massas adquiriu para defender 0 governo do golpe de 2002 e dos locautes patronais, por um lado; e o descumprimento dos contratos coletivos, o alto custo de vida, o desemprego, por outro lado, motivaram a intensificação das mobilizações operárias e populares, acirrando a luta de classes: "Nada más, en mayo la inflación fue de 3,2 y 12,4\% en lo que va del año. La realidad y los numeritos, bacen que los trabajadores nos plantemos en continuar la lucha por el aumento, vía contratación colectiva y con movilización de calles" (USI, 2008, p. 4).

\section{O governo Chávez e o processo de REORGANIZAÇÃO OPERÁRIA}

Verifica-se por parte do governo, ao mesmo tempo em que as lutas se desenvolvem, uma tentativa de absorver esse processo ou mesmo até de contê-lo, através da incorporação de dirigentes em projetos e cargos da burocracia estatal, da criação de políticas assistencialistas que tecem uma relação de dependência com diversos setores populares ${ }^{10}$, da repressão às marchas e mobilizações operárias, da criação de políticas que ameaçam a autonomia sindical e da conformação de um partido unificado que visa dissolver os demais partidos da classe trabalhadora.

Desde o início de seu mandato, Chávez se utiliza de algumas mediações para manter-se próximo aos movimentos sociais e populares. Os Círculos Bolivarianos impulsionados pelo chavismo, por exemplo, tiveram um papel fundamental na

\footnotetext{
${ }^{10}$ Segundo Lander, "[...] la dependencia de muchos de estos procesos organizativos populares de las iniciativas y el financiamiento de las políticas - con dosis frecuentes de clientelismo - dificulta la generación de experiencias organizativas autónomas" (LANDER, 2007, p. 73).
} 
defesa do governo contra o golpe de 2002. A criação dos Conselhos Comunais ${ }^{11}$, em 2006, acabou funcionando também como uma ferramenta de aproximação do governo com os setores populares.

Pode-se considerar que o governo obteve um êxito importante em sua política de aproximar as forças políticas em ascensão de seu projeto para o país. A UNT, que participou ativamente de diversas campanhas eleitorais chavistas, foi um dos pilares que possibilitou a governabilidade de Chávez diante das reações da direita em 2003. Os trabalhadores do petróleo, por sua vez, cumpriram um papel fundamental quando estabeleceram o controle operário da produção por 63 dias e derrotaram a paralisação patronal que visava derrotar o governo.

De fato, o chavismo parece ser hegemônico na esquerda venezuelana hoje. Entretanto, no decorrer das lutas, emergem contradições entre o projeto de Chávez e as reivindicações do movimento operário em ascensão. A mobilização permanente da classe operária não parece consolidar ou fortalecer a sua aliança com o governo. Ao contrário, quanto mais a luta de classes se energiza, mais entram em conflito, aumentando suas críticas e a necessidade de progredir em sua capacidade de organização para alcançar seus objetivos por conta própria.

Em Sanitários Maracay, por exemplo, num primeiro momento os trabalhadores direcionavam suas exigências somente ao patrão. Exigiam 0 respeito ao contrato coletivo, aos direitos trabalhistas e o reconhecimento do sindicato. Com o desenrolar de sua luta, passaram a exigir a nacionalização e a expropriação da fábrica. Os pronunciamentos do Ministro do Trabalho e a repressão aos operários de Sanitarios Maracay e Sidor causaram impactos importantes na relação do movimento com o governo. Pode-se perceber que ao mesmo tempo em que se intensifica no operariado e nas organizações de esquerda o debate sobre 0 socialismo e a revolução, aumentam suas críticas ao reformismo, ao burocratismo e à corrupção do governo (BUZETTO, 2008, p. 187).

Parte das organizações não aceita, por exemplo, que as eleições sindicais sejam submetidas às normas do Conselho Nacional Eleitoral, postura questionada por Chávez:

Os sindicatos não querem ter nada a ver com o partido [PSUV] e nem com o governo, querem ser autônomos. É uma espécie de chantagem: perdem de vista a luta histórica da classe operária pela revolução com o conto de que

\footnotetext{
${ }^{11} \mathrm{~A}$ criação dos Conselhos Comunais, que se assemelham muito às associações de bairros brasileiras, acabou por substituir a maior parte dos Círculos Bolivarianos, que hoje já não possuem quase nenhuma visibilidade política no país.
}

O “velho” Sujeito históRico E A Luta de Classes na Venezuela...

F. B. Rosa

$\bullet 307$ 
são autônomos, afirma Chávez em uma reunião com os trabalhadores do petróleo, em 2007 (MÁRQUUZZ, 2008).

A nacionalização da Sidor, após um ano e meio de mobilização, é vista por vários setores como o principal acontecimento político do último período. Mas, as organizações que apoiavam essa luta questionam a postura do Ministro do Trabalho José Rivero, que era contrária à estatização, e à posição de Chávez, que apoiou o acordo entre o governo e a multinacional Techint até poucos dias antes de se ver obrigado a aceitar a exigência dos trabalhadores. A nacionalização é vista, portanto, como uma vitória da mobilização operária e uma derrota da política que o governo vinha aplicando até então e que se expressou na agressão por parte da Guarda Nacional contra os sidoristas, em Março de 2007, e nas ameaças e chantagens feitas por parte do Ministro do Trabalho contra os trabalhadores. Chávez só teria nacionalizado a siderúrgica devido às pressões dos operários e à necessidade de recuperar sua imagem diante da aproximação das eleições regionais.

No caso da Sidor, a mobilização operária foi capaz de obrigar o governo a nacionalizar a empresa rompendo o acordo com a multinacional. Além disso, trouxe à tona algumas questões importantes ao operariado: bastaria substituir 0 patrão privado pelo patrão estatal? Como ficariam os 8000 trabalhadores terceirizados já que não foram integrados à empresa? Aceitariam que a empresa fosse indenizada, mesmo após ter se recusado a respeitar os direitos dos trabalhadores?

A crítica às modificações realizadas no setor petroleiro também ecoa entre as organizações envolvidas nas lutas atuais:

Las fulanas empresas mixtas son una burlay un engaño al pueblo venezolano, que cree honestamente que PDVSA ahora sí lo pertenece. Convertir en socias del lucrativo negocio petrolero a las transnacionales no tiene nada de nacionalista, ni mucho menos de defensa de nuestra soberanía. [...] Esto es realmente un absurdo que se pretende vender al pueblo venezolano como si fuera una nacionalización, siendo más bien un flagrante retroceso (USI, 2008, p. 3).

Da mesma forma, a política econômica adotada pelo presidente é um dos fatores que respinga diretamente na relação do governo com o movimento operário. 0 jornal Voz de los Trabajadores divulgou que em 11 de junho de 2008, no Hotel Alba em Caracas, o presidente anunciava algumas medidas econômicas voltadas para favorecer a alta hierarquia dos capitalistas venezuelanos e internacionais, 
através da criação de um fundo de promoção industrial, concessão de subsídios aos produtores do campo, flexibilização de tramites para aquisição de divisas, eliminação de impostos às multinacionais financeiras, convite aos representantes das associações econômicas e empresariais para serem provedores do Estado, compromisso de seguir desenvolvendo grandes projetos de infra-estrutura que trazem alta rentabilidade aos capitalistas, e uma convocatória aos capitalistas para que se "comprometan con el país y ayuden a convertir Venezuela en una potencia económica mediana" (USI, 2008, p. 2).

Mesmo organizações chavistas, devido ao acirramento da luta de classes, acabaram por reivindicar algumas bandeiras que se contradizem com este programa, como o não pagamento da dívida externa, a expropriação de fábricas sem indenização ou as exigências da queda do ex-Ministro do Trabalho e de deposição do governador do estado de Aragua, devido à repressão contra os trabalhadores.

Estas contradições culminam na concepção, defendida por alguns setores, de que

[... ] la disposición a movilizarse y luchar sigue vigente entre los trabajadores y el pueblo, y es el dique de contención contra el avance de la burguesía, el imperialismo y sus partidos, los cuales se han venido recuperando relativamente, tanto económica como políticamente, gracias a la impunidad reinante y a la política de colaboración de clases del gobierno. En ese sentido podemos afirmar que las luchas se radicalizan. Y el pueblo ejecuta con sus propias manos lo que el gobierno, sus burócratas y sus "empresarios socialistas" se niegan a hacer (C-CURA, 2008, p. 3).

Pode-se perceber que o que se denomina como processo de reorganização do movimento operário e sindical não indica necessariamente vitórias imediatas da classe operária. Pelo contrário, os fatos relatados tratam muitas vezes de atentados que a burguesia e/ou o governo cometem contra os trabalhadores, como é o caso da ameaça de demissão, da repressão física, do desrespeito aos seus direitos, do não reconhecimento dos sindicatos, dos salários rebaixados e das condições precárias de trabalho. 0 que se procurou ressaltar é que está havendo um progresso quanto à capacidade da classe operária, assim como de outros setores da classe trabalhadora, em responder a estes ataques de forma organizada.

0 presente texto buscou apresentar alguns elementos que ratificam a importância política do operariado na luta de classes venezuelana - apesar de seu 
número extremamente reduzido no país. Trata-se de um setor que ainda ocupa um lugar estratégico nas lutas e que está menos propenso a cooptação pelo projeto do governo, uma vez que a maior contradição que enfrenta se reproduz a cada dia no chão de fábrica e não pode ser inteiramente resolvida pelos programas assistencialistas de Chávez. A oposição entre os interesses do operariado e dos "patrões" se torna evidente no local de trabalho cotidianamente. E é no terreno deste conflito que se torna mais claro o posicionamento do governo chavista e para onde caminha a "Revolução Bolivariana". Por isso, parece ser possível afirmar que apesar das dificuldades que enfrenta, o operariado venezuelano concentra em suas mãos a imensa responsabilidade de conduzir a luta política do país, agregando os diversos setores das camadas populares e se somando à luta internacional contra 0 capitalismo, rumo à construção de uma outra sociedade.

\section{Conclusão}

Não se pretende aqui negar que o "mundo do trabalho" vem sofrendo alterações. Muito menos desconsiderar a importância dos novos atores que vêm surgindo junto com essas mudanças. 0 que se procurou desenvolver neste artigo é que a ascensão de novos sujeitos, assim como a reconfiguração das forças políticas não pode significar que as ciências sociais e, principalmente o marxismo, fechem os olhos para o movimento operário. Este "velho" sujeito, apesar de ter passado por "maus bocados", tem ainda a potencialidade de se reorganizar, uma vez que ainda sofre, cotidianamente, com o conflito capital/trabalho. Possui, portanto, a potencialidade de transformar a sociedade, e não cumpre aí um papel secundário. Por outro lado, parece que suas condições de vitória, tanto nas lutas cotidianas, quanto na luta estratégica, depende cada vez mais da aliança com os movimentos sociais e demais setores populares. Neste sentido, concordamos com a argumentação de Ricardo Antunes, quando afirma que:

Ao contrário, entretanto, daqueles que propugnaram pelo 'fim do papel central da classe trabalhadora' no mundo atual (Habermas, 1989; Gorz, 1990 e Offe, 1989), o desafio maior da classe-que-vive-do-trabalho, nesta virada do século XX para o XXI, é soldar os laços de pertencimento de classe existentes entre os diversos segmentos que compreendem 0 mundo do trabalho, procurando articular desde aqueles segmentos que exercem um papel central no processo de criação de valores de troca até aqueles segmentos que estão mais à margem do processo produtivo mas que, pelas condições precárias 
em que se encontram, constituem-se em contingentes sociais potencialmente rebeldes frente ao capital e suas formas de (des) sociabilização (ANTUNES, 1999, p. 192).

Contudo, insistimos aqui em retomar a discussão sobre o papel do proletariado tradicional, a despeito do rumo oposto tomado pelas ciências sociais, porque consideramos ainda seu posicionamento estratégico no processo produtivo e sua experiência histórica de luta como fatores imprescindíveis para a obtenção da vitória de toda a classe trabalhadora no processo de transformação social.

No caso específico da Venezuela acreditamos ser possível afirmar que a reorganização do movimento operário de forma autônoma é um elemento fundamental, com grandes possibilidades de condução do processo político e de influência sobre os demais setores populares, já que por estar inserido diretamente no conflito cotidiano de classes no próprio processo de produção e vivenciar suas contradições, está menos propenso ao discurso de "colaboração de classes" e de "unidade nacional", propagandeado pelo governo.

Não é possível afirmar ainda a condição duradoura ou não da reorganização no país. A durabilidade do processo irá depender de muitos fatores, como o acirramento da luta de classes e a capacidade ou não do governo em absorver as forças políticas para o projeto nacional bolivariano. Além disso, as vitórias ou derrotas que o movimento operário venha a sofrer nas lutas cotidianas poderiam alimentar ou diminuir o ritmo da reorganização.

Por enquanto, é possível perceber que existe um limite na capacidade do governo de absorver ou conter o movimento. A baixa qualidade de vida, a super-exploração, os baixos salários, as condições de insegurança no trabalho e a repressão ainda são problemas que assolam o operariado. Frente a isso se intensifica, durante o governo Chávez, a reorganização da classe operária, que adquire uma expressão política. Criam-se novos partidos, sindicatos e centrais, aumentam as mobilizações e protestos que aos poucos se voltam contra a própria política de Chávez. Além disso, o governo não pôde se poupar de um desgaste devido à repressão utilizada contra os trabalhadores mobilizados que disseminam as propostas de controle operário e de expropriação sem indenização.

Esse processo de reorganização operária, contudo, não indica que em curto ou médio prazo a classe rompa com o governo e consolide uma alternativa de direção classista de massas, mesmo no terreno eleitoral. Porque apenas um setor ainda minoritário vislumbra a necessidade de um governo propriamente 
proletário para pôr fim à sociedade de classes. Grande parte das organizações envolvidas nos processos de luta parece ainda não ter rompido com a proposta chavista, mas detecta cada vez mais os seus limites para resolver os problemas das classes trabalhadoras.

\section{REFERÊNCIAS}

AMORIM, José Henrique Domiciano. Teoria social e reducionismo analítico: para uma crítica a debate sobre a centralidade do trabalho. Caxias do Sul: Educs, 2006.

ANDERSON, Perry. Balanço do neoliberalismo. In: GENTILI, Pablo; SADER, Emir (Org.). Pós-neoliberalismo: as políticas sociais e o estado democrático. 5. ed. São Paulo: Paz e Terra, 2000. p. 9-28.

ANTUNES, Ricardo. Os sentidos do trabalho: ensaio sobre a afirmação e a negação do trabalho. São Paulo: Boitempo, 1999.

ARENAS, Nelly. El projecto chavista: entre el viejo e el nuevo populismo. Cuestiones Políticas, Zulia, n. 36, p. 35-69, jan./jun. 2006.

BUZETTO, Marcelo. As lutas sociais e políticas na Venezuela bolivariana. Lutas sociais, São Paulo, n. 19/20, p. 176-192, 2008.

C-CURA. Conclusiones Plenário Nacional. Caracas, 2008. mimeo.

CORMENZANA, Pablo. La clase obrera y la lucha por el socialismo en Venezuela. Disponível em: <http://www.controlobrero.org/content/view/274/1/>. Acesso em: 4 jun. 2009.

GALVÃO, Andréia. Marxismo e movimentos sociais. In: VI SEMINÁRIO LUTAS E RESISTÊNCIA, 6., 2010, Londrina. Anais... Londrina: UEL, 2010.

JIMÉNEZ, Juan E. Romero; RUBIO, José R. Larez. Transición política, democracia y espacio público en Venezuela. Cuestiones Políticas, Zulia, n. 28, p. 71-97, jun. 2002.

LANDER, Edgardo. El estado y las tensiones de la participación popular en Venezuela. OSAL, Buenos Aires, ano 8, n. 22, set. 2007. Disponível em: <http:// bibliotecavirtual.clacso.org.ar/ar/libros/osal/osal22/D22Lander.pdf >. Acesso em: 10 jun. 2009.

MALDONADO, Miriam Rincón de; FERNÁNDEZ, María Alejandra; RODRÍGUEZ, Hudilú. Algunas consideraciones sobre los actores políticos en la democracia 
venezolana desde una perspectiva sistémica. Cuestiones Políticas, Zulia, n. 32, p. 64-100, 2004.

MARINGONI, Gilberto. A Venezuela que se inventa. São Paulo: Fundação Perseu Abramo, 2004.

MÁRQUEZ, Humberto. Venezuela: autonomia sindical em perigo. Disponível em: $\quad<$ http://www.esquerda.net/index2.php?option=com_content\&do_ pdf=1\&id=2846> . Acesso em: 13 junho 2008.

MAYA, Margarita López; SMILDE, David; STEPHANY, Keta. Protesta y cultura en Venezuela. Buenos Aires: Clacso, 2002.

MORENO, Yonie; SANABRIA, William. Las empresas en cogestión y ocupadas en Venezuela, la lucha por el control obrero y el socialismo. Disponível em: <http://www.controlobrero.org/content/view/24/30/> Acesso em: maio 2007.

ORGANISTA, José Henrique Carvalho. O debate sobre a centralidade do trabalho. São Paulo: Expressão Popular, 2006.

UNIDAD SOCIALISTA DE IZQUIERDA (USI). Voz de los trabajadores, Venezuela, ano 1, n. 4, jun. 2008. 